\title{
ASSOCIATION OF TYPE 2 DIABETES MELLITUS WITH ABO AND RH BLOOD GROUP
}

\author{
Asma Tasneem, Samina Naeem*, Nasir Uddin, Maria Farid, Shehneela Jabeen, Ammara Hafeez \\ Combined Military Hospital Lahore/National University of Medical Sciences (NUMS) Pakistan, *CMH Lahore Medical and Dental College, Lahore/ \\ National University of Medical Sciences (NUMS) Pakistan
}

\begin{abstract}
Objective: To find out the association of type 2 diabetes mellitus with $\mathrm{ABO}$ and Rh blood groups.

Study Design: Cross sectional study.

Place and Duration of Study: Department of Haematology, Combined Military Hospital Lahore, from Jul to Dec 2020.

Methodology: A total 179 patients with type 2 diabetes mellitus and 50 healthy individuals were inducted into the study. Five $(5 \mathrm{ml})$ blood from the patients was taken via aseptic venipuncture in a tube containing EDTA. HbA1C was generated through automated analyzer Cobas c501 and blood grouping was carried out using tube method by an experienced technician.

Results: A total of $179(77.8 \%)$ individuals with diabetes mellitus type 2 and $50(21.7 \%)$ healthy cases were inducted into the study as a control group. A statistically significant difference was observed with blood group B being the most prevalent among them $(p=0.001)$. There was a greater frequency of Rh-negative blood group in patients having diabetes mellitus type 2 as compared to the control group.

Conclusion: There is a strong association found between $\mathrm{ABO}$ and $\mathrm{Rh}$ blood group with diabetes mellitus type 2. Blood group $\mathrm{B}$ negative was the most common among the patients having diabetes mellitus type 2 . Blood group $\mathrm{O}$ positive showed the least association.
\end{abstract}

Keywords: ABO blood grouping, Diabetes mellitus, Rhesus blood group system.

How to Cite This Article: Tasneem A, Naeem S, Uddin N, Farid M, Jabeen S, Hafeez A. Association of Type 2 Diabetes Mellitus with ABO and Rh Blood Group. Pak Armed Forces Med J 2021; 71(5): 1848-1851. $\quad$ doi: https://doi.org/10.51253/pafmj.v71i5.6130

This is an Open Access article distributed under the terms of the Creative Commons Attribution License (https://creativecommons.org/licenses/by-nc/4.0/), which permits unrestricted use, distribution, and reproduction in any medium, provided the original work is properly cited.

\section{INTRODUCTION}

Two major human blood group antigen system which are of prime importance in the field of transfusion medicine includes $\mathrm{ABO}$ and Rhesus (Rh). ABO blood groups antigens are inherited on the surface of red blood cells in addition to other tissues ${ }^{1}$. In 1901 Karl Landsteiner was the first person who discovered this $\mathrm{ABO}$ blood grouping. The type of blood group that a patient will have depends upon the presence or absence of A, B and Rh genes. Since $19^{\text {th }}$ century, there has been an assorted challenge to find out a possible relationship between various metabolic and malignant diseases and $\mathrm{ABO}$ blood groups ${ }^{2}$. A certain blood group can predispose the patient to having an increased susceptibility to a specific disease like the persons having blood group $\mathrm{O}$ are predisposed to peptic ulceration and the persons having blood group A have a more susceptibility of developing stomach carcinom$\mathrm{as}^{3}$. Other diseases associated with $\mathrm{ABO}$ blood groups include hepatitis B, vascular diseases, and abdominal aortic aneurism etc ${ }^{4}$.

One of the most common medical problems in our community is diabetes mellitus, having significant

Correspondence: Dr Asma Tasneem, Department of Haematology, Combined Military Hospital Lahore Pakistan

Received: 18 Jan 2021; revision received: 28 May 2021; accepted: 03 Jun 2021 mortality and morbidity. Main characteristic feature of this disease is presence of hyperglycaemia due to a defect in insulin secretion or an increase resistance to insulin at cellular level ${ }^{5}$. It is divided into two subtypes. Type 1 or the insulin dependent diabetes mellitus and type 2 the non-insulin dependent diabetes mellitus. Type 2 diabetes is the most common form accounting for around $90-95 \%$ of all the diabetic cases worldwide 6 .

$\mathrm{ABO}$ blood grouping and diabetes mellitus has a genetic basis. Some environmental factors may play a significant role in the development of their genetic expressions, they both might have an association with each other. A positive association may mean that there will be an increased susceptibility of acquiring or developing this condition. Lack of association may reflect a specific blood group to be a protective factor against diabetes. Therefore, the objective of this study was to check association of $\mathrm{ABO}$ and $\mathrm{Rh}$ blood group with diabetes mellitus type-2.

\section{METHODOLOGY}

This cross sectional study was conducted at the Haematology department, Combined Military Hospital, Lahore from July to December 2020 after approval from ethics committee review board IRB\#196/2020. Written informed consents were taken from patients. 
Sampling was non-probability consecutive sampling technique. A sample size of 179 was calculated using frequency of $\mathrm{Rh}+$ blood group in diabetes mellitus type 2 as $86.6 \%$, keeping power of test $80 \%$ and alpha $=0.05$ using open EPI sample size calculator version 3.017 .

Inclusion Criteria: All the patient with type 2 diabetes reporting to the department of Medicine for routine checkup were included in the study, irrespective of age, gender and duration of disease.

Exclusion Criteria: Patients with other comorbid conditions like gastric or cardiac problems were excluded from the study.

American Diabetic Association defined diabetes mellitus by fasting plasma glucose level of $>126 \mathrm{mg} / \mathrm{dl}$ or 2-hour OGTT plasma glucose level of $>200 \mathrm{mg} / \mathrm{dl}$ or $\mathrm{HbAIC}>6.5 \%^{8}$. Fifty healthy patients were taken as control group.A $5 \mathrm{ml}$ blood sample was taken in the EDTA tube from the antecubital vein. Blood grouping was carried out using direct tube method by an experienced technician. A 5\% cell suspension was prepared by mixing one drop of packed cells with 19 drops of buffered normal saline. Label the tube as A, B, AB, and $\mathrm{Rh} \mathrm{D}$. Place one drop of antiserum in each tube. Add a drop of test cell suspension into each of the tube containing anti-serum. Mix gently and centrifuge tubes for 15 second at 3500rpm. Macroscopically and microscopically agglutination was checked and result was recorded.

Data was analyzed using SPSS-25. Data normality was assessed using Shapiro wilk test. This showed that data was not normally distributed. Patients were divided into 2 groups based on presence or absence of diabetes mellitus type 2. Mean and SD was calculated for numerical variables. Percentage and frequency was calculated for categorical variables. Chi square test was used for establishing association between qualitative variables among various groups. The $p$-value of $\leq 0.05$ was considered statistically significant.

\section{RESULTS}

A total of $179(77.8 \%)$ individuals with diabetes mellitus type 2 and 50 (21.7\%) healthy cases were inducted into the study as a control group. Mean age of the patients was 47.2 years SD 7.8 years with a range of 34-65 years. Out of total 229 patients 106 (46.1\%) were males and $123(53.5 \%)$ were females.

Blood group B was the most prevalent of all with a percentage of 78 (33.9\%), followed by blood group A, $66(28.7 \%)$, blood group AB, $48(20.9 \%)$ and blood group O, $37(16.1 \%)$. Rh-ve patients had a higher frequency $127(55.4 \%)$ as compared to $\mathrm{Rh}+$ ve individuals $102(44.6 \%)$. Distribution of various blood groups is depicted in the Figure-1.

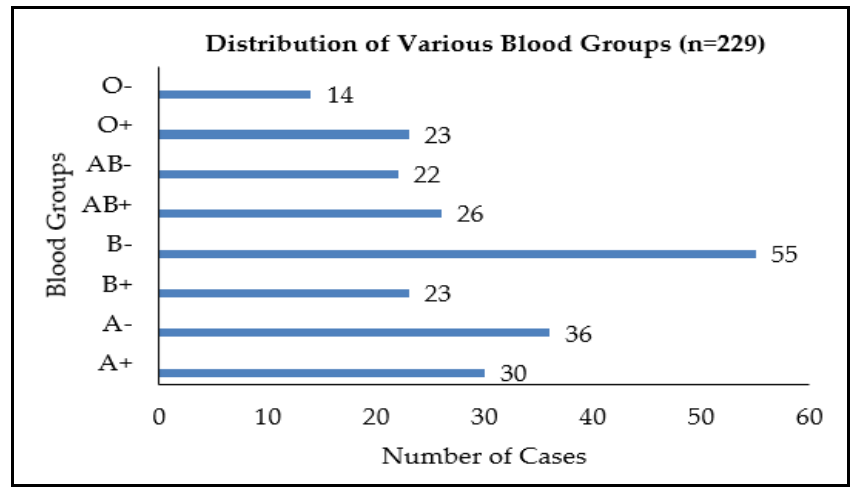

Figure-1: Distribution of blood groups $(\mathbf{n}=229)$.

When we compared the distribution of $\mathrm{ABO}$ blood groups in patients with diabetes mellitus type 2 . A statistically significant difference was observed with blood group $B$ being the most prevalent among them $(p=0.001)$. There was a greater prevalence of Rh negative blood group in patients having diabetes mellitus type 2 as compared to the control group $(p=0.001)$ as shown in the Table.

Table: Association of ABO blood group with diabetes mellitus type 2 .

\begin{tabular}{l|c|c|c}
\hline \multirow{2}{*}{$\begin{array}{l}\text { Blood } \\
\text { Group }\end{array}$} & \multicolumn{2}{|c|}{ Diabetes Mellitus Type 2 } & \multirow{2}{*}{$\begin{array}{c}\boldsymbol{1} \text { - } \\
\text { value }\end{array}$} \\
\cline { 2 - 3 } $\mathrm{A}$ & Present $\mathbf{n = 1 7 9}$ & Absent $\mathbf{n}=\mathbf{5 0}$ & \\
\hline $\mathrm{B}$ & $48(26.8 \%)$ & $18(36 \%)$ & \\
\hline $\mathrm{AB}$ & $71(39.6 \%)$ & $7(14 \%)$ & \multirow{2}{*}{0.001} \\
\hline $\mathrm{O}$ & $40(22.3 \%)$ & $8(16 \%)$ & \\
\hline $\mathrm{Rh}+\mathrm{ve}$ & $20(11.2 \%)$ & $17(34 \%)$ & \\
\hline $\mathrm{Rh}-\mathrm{ve}$ & $68(37.9 \%)$ & $34(68 \%)$ & \multirow{2}{*}{0.001} \\
\hline
\end{tabular}

Blood group B-ve $(n=53)$ was most prevalent in diabetes mellitus type 2 group, followed by A-ve $(n=29)$. However, in control group the most prevalent blood group was $\mathrm{O}+\mathrm{ve}(\mathrm{n}=14)$ followed by $\mathrm{A}+\mathrm{ve}(\mathrm{n}=$ 11). This difference was statistically significant $p=0.001$ as shown in the Figure-2.

\section{DISCUSSION}

During mid 1950's the relationship between blood groups and systemic disease were identified for the first time. Other diseases associated with $\mathrm{ABO}$ blood groups include hepatitis B, vascular diseases, and abdominal aortic aneurysm etc.

In this study the most prevalent blood group in the control group was A (36\%) followed by blood 


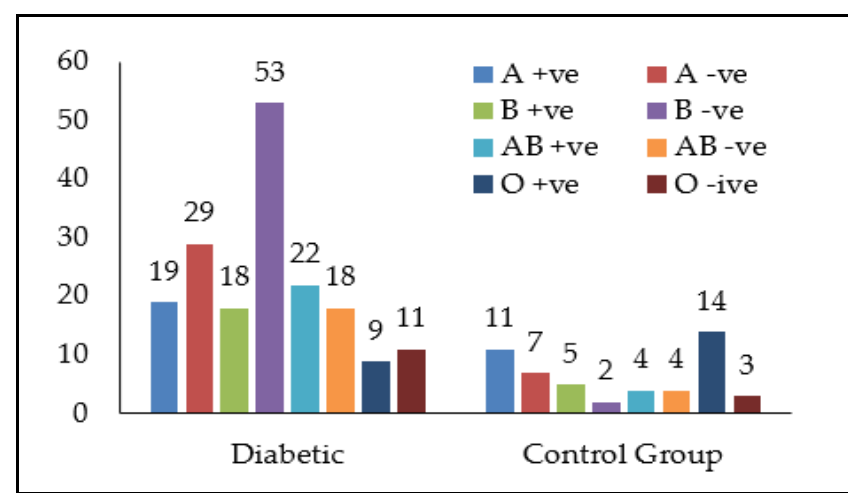

Figure-2: distribution of various blood groups among diabetics $(n=179)$ and control group $(n=50)$.

group $\mathrm{O}(34 \%)$. The control population was mostly $\mathrm{Rh}+\mathrm{ve}(68 \%)$. Similar results were reported by a study conducted by Khattak et al, who concluded that out of total 17141 males and 5756 females $90.99 \%$ and $87.56 \%$ were $\mathrm{Rh}+\mathrm{ve}$ respectively ${ }^{9}$. Sabir et al, in their study concluded that blood group $B$ was most prevalent among people of Safdarabad, followed by $\mathrm{O}, \mathrm{A}$ and $\mathrm{AB}$ respectively. A greater percentage of people were $R h$ $+\mathrm{ve}^{10}$.

In our stream of patients, we found that blood group B was most closely associated with diabetes mellitus. The least associated blood group with diabetes mellitus was $\mathrm{O}$ blood group. There were more $\mathrm{Rh}$ negative cases having diabetes mellitus type 2. Similar results were stated by Meo et al ${ }^{11}$. Contradictory results were shown by study conducted by Alanazi et al. Who concluded that most prevalent blood group among the diabetic patients was $\mathrm{O}(38.7 \%)$ and around three quarters were $\mathrm{Rh}$ positive $(74.8 \%)^{12}$.

The most probable explanation for the development of $\mathrm{ABO}$, Rh blood group and its association with diabetes mellitus type 2 is still a topic of much debate. Recent studies based on the genome wide associations have revealed that presence of blood group antigens both $\mathrm{ABO}$ and $\mathrm{RH}$, amplifies the inflammatory response of the body. Two serum markers of inflammation are linked with single nucleotide polymorphism at the ABO locus. These markers are known as tumour necrosis factor a and soluble intercellular adhesion molecule $1^{13}$. Development of inflammation is the main etiological factor responsible for insulin resistance and development of diabetes.

No significant association was found between $\mathrm{ABO}$ blood group and diabetes mellitus type 2 in a study conducted by Khansa et al ${ }^{14}$. A study by Al-Ani et al. suggested that there was a significant association between genetically determined $\mathrm{ABO}$ and $\mathrm{Rh}$ blood group system with diabetes mellitus type 2 . Blood group $A B$ had the least contribution whereas blood group $\mathrm{A}$ and $\mathrm{B}$ however posed a greater risk in developing this condition ${ }^{15}$. Results consistent with our study were revealed by Dharmendra et al. Who stated that odds ratio suggested that blood group $\mathrm{B}$ and blood group $\mathrm{O}$ were at a greater risk of developing diabetes but the result of chi square test showed no significant association $^{16}$. Reyhane et al, suggested that blood group $\mathrm{O}$ was most common among patients with diabetes mellitus type 2. Blood group $\mathrm{AB} \mathrm{Rh}$ negative had the least frequency ${ }^{17}$.

Ebeye et al showed that contradictory findings, suggesting no significant difference in the distribution of $\mathrm{ABO}$ blood groups in diabetics and non-diabetics. However, the diabetics had a lesser prevalence of blood group $\mathrm{A}$ as compared to control group. Blood group $\mathrm{AB}$ was more prevalent among the diabetics ${ }^{18}$. Andrea et al, found no significant association between $\mathrm{Rh}$ blood groups and diabetes mellitus. Whereas ABO blood groups were different between gestational diabetes mellitus and control group with an odds ratio of $0.25^{19}$. With an increasing trend towards urbanization in our communities of the rural areas and a global increase in the incidence of diabetes, it is important to carry out large scale studies to document association of various risk factors associated with this common disease. It will prevent its occurrence and identify the prone individuals. It will pave way for its early recognition and institution of optimum treatment.

\section{CONCLUSION}

We have found a strong association between $\mathrm{ABO}$ and $\mathrm{Rh}$ blood group with diabetes mellitus type 2 . Blood group $\mathrm{B}$-ve was the most prevalent among the patients having diabetes mellitus type 2 . Blood group $\mathrm{O}+\mathrm{ve}$ showed the least association. $\mathrm{Rh}$ negative blood group may predispose a patient to having diabetes mellitus type 2 . Blood group $\mathrm{O}$ may play a protective role against development of diabetes mellitus type 2 in an individual. Blood groups $A$ and $A B$ showed no significant association with diabetes mellitus.

\section{Conflict of Interest: None.}

\section{Authors' Contribution}

AT: Direct contribution to conception, design, analysis and interpretation, SN: Intellectual contribution to analysis, literature review, manuscript review, NU: Intellectual contribution to analysis, literature review, manuscript review, MF: Literature review, analysis, manuscript preparation, SJ: Literature review, analysis, manuscript preparation, $\mathrm{AH}$ : Literature review, analysis, manuscript preparation. 


\section{REFERENCES}

1. Rahorst L, Westhoff CM. ABO and H Blood Group System. In Transfusion Medicine and Hemostasis 2019 Elsevier, Second Edition (pp. 139-147), [Internet] Available from: https://www. elsevier.com/books/transfusion-medicine-andhemostasis/shaz/978-0-12-397164-7

2. Groot HE, Villegas Sierra LE, Said MA, Lipsic E, Karper JC, van der Harst P. Genetically determined $\mathrm{ABO}$ blood group and its associations with health and disease. Arterioscler Thromb Vasc Biol 2020; 40(3): 830-838.

3. Teshome Y, Mekonen W, Birhanu Y, Sisay T. The association between $\mathrm{ABO}$ blood group distribution and peptic ulcer disease: a cross-sectional study from Ethiopia. J blood Med 2019; 10(4): 193-197.

4. Yu H, Xu N, Li ZK, Xia H, Ren HT, Li N, et al. Association of $\mathrm{ABO}$ blood groups and risk of gastric cancer. Scand J Surg 2020; 109(4): 309-313.

5. Norhammar A, Bodegard J, Nyström T, Thuresson M, Eriksson JW, Nathanson D. Incidence, prevalence and mortality of type 2 diabetes requiring glucose-lowering treatment, and associated risks of cardiovascular complications: a nationwide study in Sweden, 2006-2013. Diabetol 2016; 59(8): 1692-1701.

6. Zheng Y, Ley SH, Hu FB. Global aetiology and epidemiology of type 2 diabetes mellitus and its complications. Nat. Rev Endocrinol 2018; 14(2): 88-92.

7. Oner C, Dogan B, Telatar B, Celik Yagan CF, Oguz A. Frequency of $\mathrm{ABO} /$ Rhesus blood groups in patients with diabetes mellitus. J Coll Physicians Surg Pak 2016; 26(1): 74-75.

8. Diagnosis|ADA. Diabetes.org. 2021, [Internet] Available from: https://www.diabetes.org/a1c/diagnosis (Accessed: May 24 2021).

9. Khattak ID, Khan TM, Khan P, Shah SM, Khattak ST, Ali A. Frequency of $\mathrm{ABO}$ and Rhesus blood groups in District Swat, Pakistan. J Ayub Med Coll Abbottabad 2008; 20(4): 127-129.
10. Sabir A, Iftikhar A, Ijaz MU, Hussain G, Rasul A, Iqbal RK, et al. Retrospective study of frequency of $\mathrm{ABO}$ and Rhesus blood group among population of Safdarabad and Faisalabad cities of Pakistan. BMC Res Notes 2021; 14(1): 1-5.

11. Meo SA, Rouq FA, Suraya F, Zaidi SZ. Association of ABO and Rh blood groups with type 2 diabetes mellitus. Eur Rev Med Pharmacol Sci 2016; 20(2): 237-242.

12. Alanazi MA, Alkhidhr MA, Alhadhari AM, Al-Hathloul AW, Alsharif EJ, Albahli SF, et al. Association of Diabetes Mellitus with ABO Blood Groups \& Rh with. Egypt J Hosp Med 2018; 73(4): 6535-6540.

13. Johansson $\AA$, Alfredsson J, Eriksson N, Wallentin L, Siegbahn A. Genome-wide association study identifies that the $\mathrm{ABO}$ blood group system influences interleukin-10 levels and the risk of clinical events in patients with acute coronary syndrome. PloS one 2015; 10(11): e0142518

14. Albaroodi KA, Hatef ZS. Association between ABO blood group and Diabetes Mellitus. Ann Trop Med Public Health 2019; 22(2): SPe110.

15. Al-Ani L, Mahmood HM, Abdulhaleem N. Genetically determined $\mathrm{ABO}$ and $(\mathrm{Rh})$ rhesus blood groups and Their associations with diabetes mellitus. Sys Rev Pharm 2020; 11(4): 604-608.

16. Dodiya D, Patel A, Jadeja J. Association of ABO blood groups with diabetes mellitus. Int. J Basic Appl Physiol 2016; 5(1): 63-66.

17. Azizi R, Manoochehry S, Razavi-Ratki SK, Seyed Hosseini SM, Vakili M, Namiranian N, et al. Distribution of ABO and Rh blood groups among diabetes type 2 patients in yazd diabetes research center (2015-2016). Iran J Diabet Obes 2016; 8(4): 191-195.

18. Ebeye MO, Aigbiremolen AA, Esegbue PR, Ubom RE, Odigie $\mathrm{MO}$, Igweh JC. Association between ABO, rhesus blood groups, and type II diabetes mellitus among the urhobos. Asian Hematol Res J 2018; 1(1): 1-6.

19. Huidobro MA, Torres CD, Paredes F. Association of ABO blood groups with gestational diabetes mellitus. Revista Medica de Chile 2017; 145(4): 431-435. 